\title{
Cornuside I promoted osteogenic differentiation of bone mesenchymal stem cells through PI3K/Akt signaling pathway
}

\author{
Feng Gao ${ }^{1 \dagger}$, Sheng-Li Xia ${ }^{1 \dagger}$, Xiu-Hui Wang ${ }^{1}$, Xiao-Xiao Zhou ${ }^{1}$ and Jun Wang ${ }^{2^{*}}$
}

\begin{abstract}
Background: Osteoporosis is a common disease closely associated with aging. In this study, we aimed to investigate the role of Cornuside I in promoting osteogenic differentiation of bone mesenchymal stem cells (BMSCs) and the potential mechanism.
\end{abstract}

Methods: BMSCs were isolated and treated with different concentrations of Cornuside I (0, 10, 30, $60 \mu \mathrm{M})$. Cell proliferation was analyzed by Cell Counting Kit-8 (CCK-8) assay. RNA sequencing was performed on the isolated BMSCs with control and Cornuside I treatment. Differentially expressed genes were obtained by the R software. Alkaline phosphatase (ALP) staining and Alizarin Red Staining (ARS) were performed to assess the osteogenic capacity of the NEO. qRT-PCR and western blot were used to detect the expression of osteoblast markers.

Results: Cornuside I treatment significantly improved BMSC proliferation. The optimal dose of Cornuside I was 30 $\mu \mathrm{M}(P<0.05)$. Cornuside I dose dependently increased the ALP activity and calcium deposition than control group $(P<0.05)$. A total of 704 differentially expressed genes were identified between Cornuside I and normal BMSCs. Cornuside I significantly increased the PI3K and Akt expression. Moreover, the promotion effects of Cornuside I on osteogenic differentiation of BMSCs were partially blocked by PI3K/Akt inhibitor, LY294002.

Conclusion: Cornuside I plays a positive role in promoting osteogenic differentiation of BMSCs, which was related with activation of PI3K/Akt signaling pathway.

Keywords: Cornuside I, Bone mesenchymal stem cells, PI3K/Akt signaling pathway

\section{Background}

Osteoporosis (OP) is a systemic metabolic bone disease caused by decreased bone density and bone mass $[1,2]$. $\mathrm{OP}$ can easily lead to fracture [3]. The estimated number of people worldwide suffering from OP will exceed 20 million by $2030[4,5]$. Over half of Americans 50 years and older have osteoporosis or low bone mass $[6,7]$.

\footnotetext{
* Correspondence: hongnai19690215@163.com

${ }^{\dagger}$ Feng Gao and Sheng-Li Xia contributed equally to this work.

${ }^{2}$ Department of Orthopedics, Shanghai Fifth People's Hospital Affiliated to

Fudan University, No. 801, Heqing Road, Minhang District, Shanghai 200240, China

Full list of author information is available at the end of the article
}

The etiology of OP is still unknown, and the pathogenesis remains unclear [8].

Bone formation is a developmental process involving the differentiation of mesenchymal stem cells (MSCs) into osteoblasts [9]. The decreased ability of osteogenic potential of osteoblasts from MSCs is the major risk of OP [10]. Thus, promoting osteogenic differentiation is an important strategy to enhance bone mineral density and slow the development of OP [11]. So far, teriparatide is one of the most effective agents to improve the osteogenic promotion drugs in clinic [12]. Other clinical drug treatments for osteoporosis mainly include bone resorption inhibitors such as bisphosphonates and

(c) The Author(s). 2021 Open Access This article is licensed under a Creative Commons Attribution 4.0 International License, which permits use, sharing, adaptation, distribution and reproduction in any medium or format, as long as you give appropriate credit to the original author(s) and the source, provide a link to the Creative Commons licence, and indicate if changes were made. The images or other third party material in this article are included in the article's Creative Commons licence, unless indicated otherwise in a credit line to the material. If material is not included in the article's Creative Commons licence and your intended use is not permitted by statutory regulation or exceeds the permitted use, you will need to obtain permission directly from the copyright holder. To view a copy of this licence, visit http://creativecommons.org/licenses/by/4.0/ The Creative Commons Public Domain Dedication waiver (http://creativecommons.org/publicdomain/zero/1.0/) applies to the data made available in this article, unless otherwise stated in a credit line to the data. 
calcitonin [13]. The therapeutic effects of these two drugs are still controversial [14]. Therefore, finding a stronger ideal bone regeneration cytokine has become a clinical hot issue that needs to be solved urgently.

Corni Fructus, attributed to the liver and kidney meridians, has the effect of promoting blood circulation, invigorating vital energy, and treating pain all over the body [15-17]. Corni Fructus is one of the most frequently prescribed herbs in traditional Chinese medicine formula for treatment of osteoporosis in China [18]. Cornuside I, as a main active ingredient of Corni Fructus, is an iridoid glycoside extracted from Corni Fructus. Previous study has identified that Cornuside I could be used for treatment of OP [19]. However, the role and mechanism of Cornuside I in promoting osteogenic differentiation of BMSCs were still unknown. RNA-sequencing (RNA-Seq) technology is a high-throughput sequencing technology which has developed rapidly in recent years. RNA-Seq could be used to identify the differentially expressed genes between treatment and control groups, and thus was applied to identify the mechanism of Cornuside $I$ in promoting osteogenic differentiation of BSMCs.

However, the mechanism through which Cornuside I promoted osteogenic differentiation of BMSCs is unclear. In this study, we firstly performed RNA sequencing to identify the mechanism of Cornuside I in promoting osteogenic differentiation of BMSCs. Then, we performed a series of studies to identify the mechanism of Cornuside $\mathrm{I}$ in promoting osteogenic differentiation of BMSCs.

\section{Material and methods}

\section{BMSC isolation and identification}

Human bone marrow mesenchymal stem cells were generated as described previously with minor modifications. In brief, the bone marrow was diluted by adding an equal volume of DMEM containing 10\% fetal bovine serum (FBS). Bone marrow was then immediately centrifuged at $100 \times g$ for $10 \mathrm{~min}$ at room temperature. Then, cells were repeatedly blown and beaten the cell mass with a pipette to disperse the mass as much as possible. Cells were then cultured in a $37^{\circ} \mathrm{C}, 5 \% \mathrm{CO}_{2}$ incubator and changed every $48 \mathrm{~h}$ subsequently. The identification of BMSCs was conducted by evaluating their adipogenic, osteogenic, and chondrogenic differentiation potential. In brief, BMSCs were cultured into the adipogenic, osteogenic, and chondrogenic medium (Cyagen, Guangzhou, China) to identify the tri-lineage differentiation capacity. Adipogenic, osteogenic, and chondrogenic differentiation potential were stained with Oil-Red-O staining, ARS, and Alcian blue staining respectively.

\section{CCK-8 assay}

BMSCs $\left(5 \times 10^{3}\right.$ cells/well $)$ were cultured overnight, and then treated as follows: control, Cornuside I (10, 30, and
$60 \mu \mathrm{M})$. Subsequently, CCK-8 reagents $(10 \mu \mathrm{l}$; Beyotime, Shanghai, China) were added to BMSCs for $2 \mathrm{~h}$. The absorbency of the samples was measured with a microplate reader (Bio-Rad, Richmond, CA, USA) at a wavelength of $450 \mathrm{~nm}$.

\section{RNA sequencing}

RNA was reversed transcribed into cDNA and then labeling. Chip hybridization was performed using an Affymetrix (Thermo Fisher Scientific, Inc.) expression profile chip and GeneChip Hybridization Wash and Stain kit. The results were scanned with an Agilent microarray scanner and read with the Feature Extraction software 10.7 .

\section{Bioinformatic analysis}

Differentially expressed gene (DEG) analysis was performed with the $\mathrm{R}$ software, using package Bioconductor package, edgeR. $|\operatorname{logFC}|>1$ and $\mathrm{P}$ value $<0.05$ were set as the threshold for screening the DEGs. The volcano plot and heatmap analysis of regulated genes were generated by using the $\mathrm{R}$ software, version 3.3.2. Gene ontology (GO) and Kyoto Encyclopedia of Genes and Genomes (KEGG) pathway enrichment analysis was done using DAVID bioinformatics resource portal. Gene Ontology consisted of biological process (BP), molecular function (MF), and cellular component (CC). Proteinprotein interaction analysis was performed via Search Tool for the Retrieval of Interacting Genes tool (http:// string-db.org/). The Cytoscape plug-in Molecular Complex Detection (MCODE, http://apps.cytoscape.org/ apps/mcode) was employed to analyze modules.

\section{ALP and ARS}

Osteogenic differentiation capacity was identified by alkaline phosphatase (ALP) staining using an ALP staining kit according to the manufacturer's protocol. In brief, BMSCs in control and different treatment groups were fixed by $4 \%$ paraformaldehyde. Then, ALP staining solution (Millipore, UK) was added. BMSCs were then washed three times.

ARS was performed according to the manufacturer's protocol. In brief, BMSCs were fixed by $4 \%$ paraformaldehyde and then washed with PBS for three times. Then, BMSCs were added 0.1\% ARS solution (Solarbio, Beijing, China) to identify the osteogenic differentiation capacity of BMSCs. To analyze ARS activity, the ARS in stained cells was destained with $10 \%$ cetylpyridinium chloride (CPC) monohydrate solution (Sigma) for $30 \mathrm{~min}$ with shaking. The sections were observed under an optical microscope with a coupled digital camera (DM750, Leica, Wetzlar, DE, Germany). 


\section{Real-time polymerase chain reaction (RT-PCR)}

The TRIzol method (Invitrogen, Carlsbad, CA, USA) was adopted to extract the total cellular RNA, which was reversely transcribed into cDNA using an RT reagent kit (Takara, Japan). The reaction system was prepared with pre-denaturation at $94^{\circ} \mathrm{C}$ for $30 \mathrm{~s}$, denaturation at $94^{\circ} \mathrm{C}$ for $5 \mathrm{~s}$, annealing at $60^{\circ} \mathrm{C}$ for $15 \mathrm{~s}$, and extension at $72^{\circ} \mathrm{C}$ for $10 \mathrm{~s}$, and 45 cycles were amplified. Results were quantified using the comparative threshold method. The quantitative copy number of the target gene $=2^{-\Delta \Delta \mathrm{Ct}}$. The copy number of the target gene was calculated for each specimen. All the fluorescence data were converted into relative quantification, and GAPDH was the internal contrast of RUNX2, OCN, and Osterix. The primers were designed and synthesized by Guangzhou Ribo Technology Co., Ltd.

\section{Western blot}

The cells were washed by cold PBS 3 times; then, 150 $\mu \mathrm{L}$ RIPA lysate (Beyotime Biotechnology, Shanghai, China) was added. The cells were lysed in ice water by ultrasound, and the protein content was determined by the Bradford method. An equal amount of proteins was taken from each group for 10\% SDS-PAGE, and the proteins on the gel were transferred to PVDF membranes (Millipore, Bedford, MA, USA). The membranes were blocked at $4^{\circ} \mathrm{C}$ for $1 \mathrm{~h}$ and then incubated at $4^{\circ} \mathrm{C}$ overnight with the following primary antibodies: antiRUNX2 antibody (1:500; Abcam, USA), anti-Osterix antibody (1:1000; Abcam, USA), anti-OCN antibody (1: 500; Abcam, USA), anti-PI3K antibody (1:1000; Abcam, USA), anti-Akt antibody (1:300; Abcam, USA), anti-pPI3K antibody (1:500; Abcam, USA), anti-p-Akt antibody (1:100; Abcam, USA), and anti-GAPDH antibody (1: 1000; Abcam, USA). After being cleaned twice with TBST, the membranes were incubated at room temperature for $1 \mathrm{~h}$ with fluorescein-labeled goat antirabbit IgG (ab205718, 1:2000). The membrane was visualized with an ECL detection kit (Millipore, Bedford, MA, USA) using a chemiluminescence imaging system (Millipore).

\section{Statistical analysis}

Data are presented as the mean \pm standard deviation. In addition, comparisons between two groups were analyzed by the unpaired Student's t-test. One-way analysis of variance and Tukey's post hoc tests were used for comparisons between $\geq 3$ groups. $\mathrm{P}<0.05$ was considered to indicate a statistically significant difference.

\section{Results}

\section{Identification of BMSCs}

BMSCs are long and spindle shaped in appearance (Fig. 1A). The BMSCs were directly induced to form osteoblasts (Fig. 1B), chondrocytes (Fig. 1C), and adipocytes (Fig. 1D) in osteogenic, chondrogenic, and adipogenic induction medium.
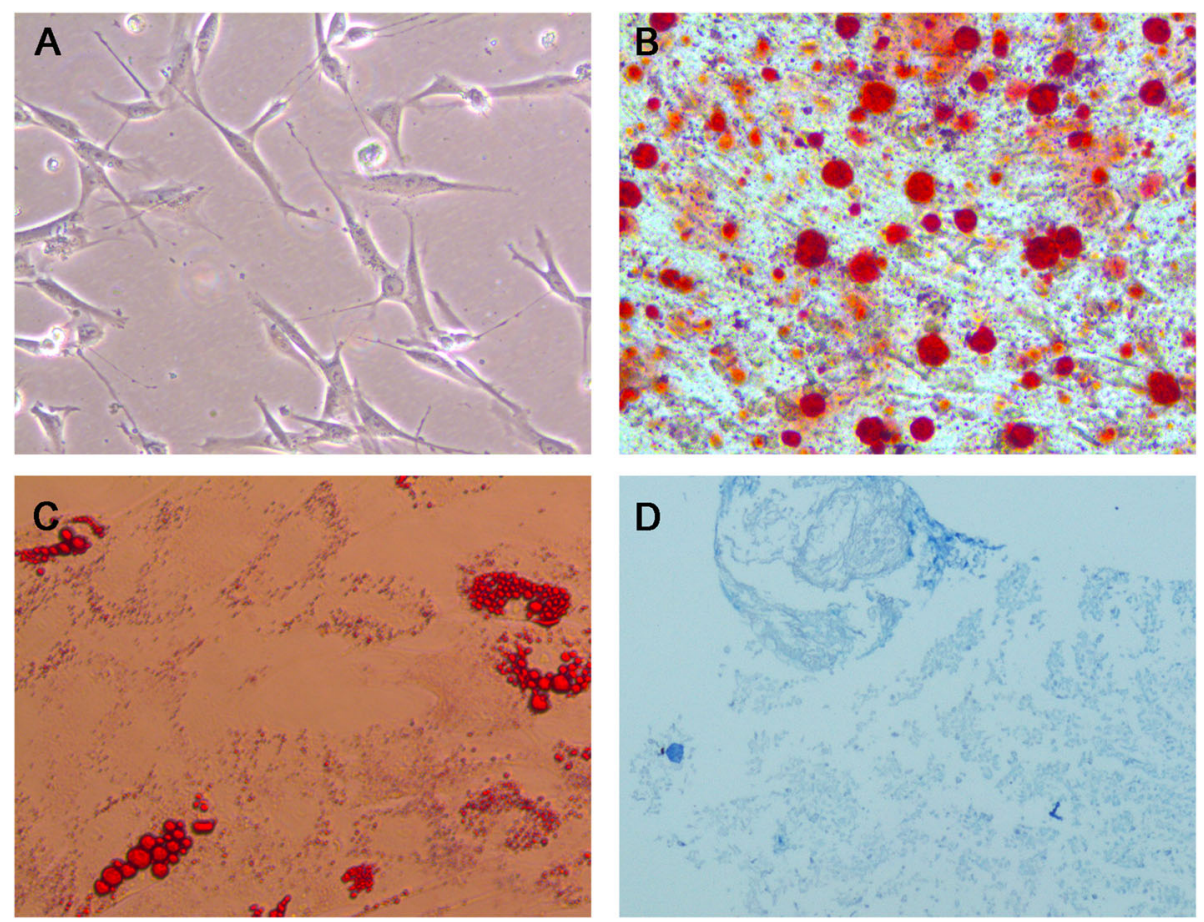

Fig. 1 Identification of the BMSCs 
Identified differentially expressed miRNAs between OA and normal samples

To analyze the differentially expressed mRNAs between normal and Cornuside I-treated BMSCs, RNA sequencing profile was subjected to bioinformatic analysis. Firstly, gene expression data were normalized using quantile normalization followed by inverse normal transformation. After normalization, the expression values were identical and could be used for further study (Fig. 2A). A total of 704 differentially expressed genes were identified between Cornuside I and normal BMSCs. Volcano plot and heatmap of the differentially expressed mRNAs can be seen in Fig. $2 \mathrm{~B}$ and $\mathrm{C}$ respectively.

\section{GO and KEGG pathway analysis of the differentially expressed genes}

The BP of the differentially expressed genes was as follows (Fig. 3A): cell division, mitotic nuclear division, sister chromatid cohesion, DNA replication, chromosome segregation, G1/S transition of mitotic cell cycle, mitotic metaphase plate congression, DNA replication initiation, regulation of transcription involved in G1/S transition of mitotic cell cycle, and mitotic sister chromatid segregation. The MF of the differentially expressed genes was as follows (Fig. 3B): midbody, condensed chromosome kinetochore, chromosome, centromeric region, spindle, spindle pole, cytosol, kinetochore, extracellular space, kinesin complex, and spindle midzone. The $\mathrm{CC}$ of the differentially expressed genes was as follows (Fig. 3C): protein binding, microtubule binding, microtubule motor activity, ATP binding, ATP-dependent microtubule motor activity, plus-end-directed, identical protein binding, heparin binding, protein homodimerization activity, extracellular matrix binding, and insulin-like growth factor II binding. The KEGG pathway of the differentially expressed genes was as follows (Fig. 3D): PI3K-Akt signaling pathway, DNA replication, p53 signaling pathway, purine metabolism, pyrimidine

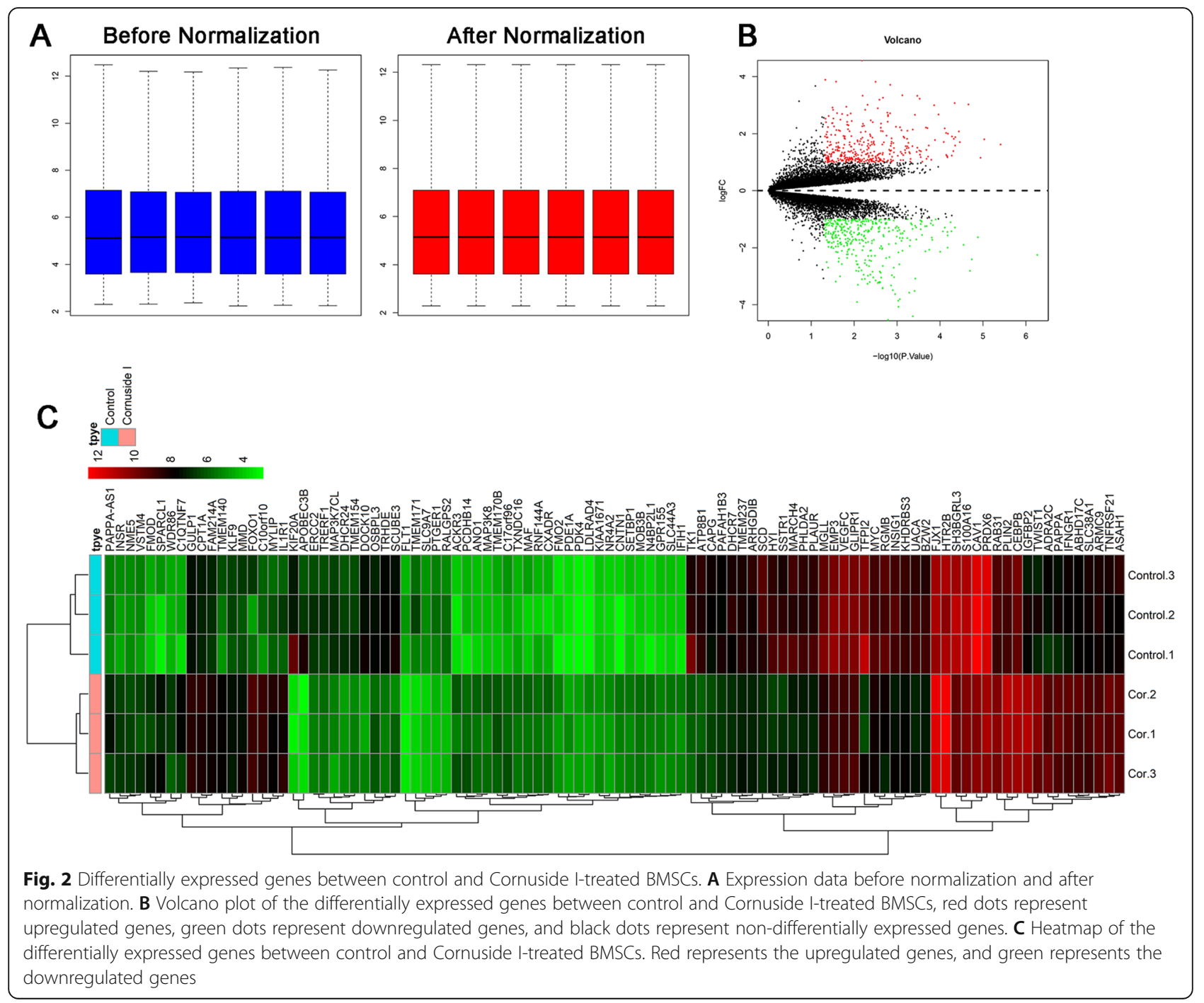




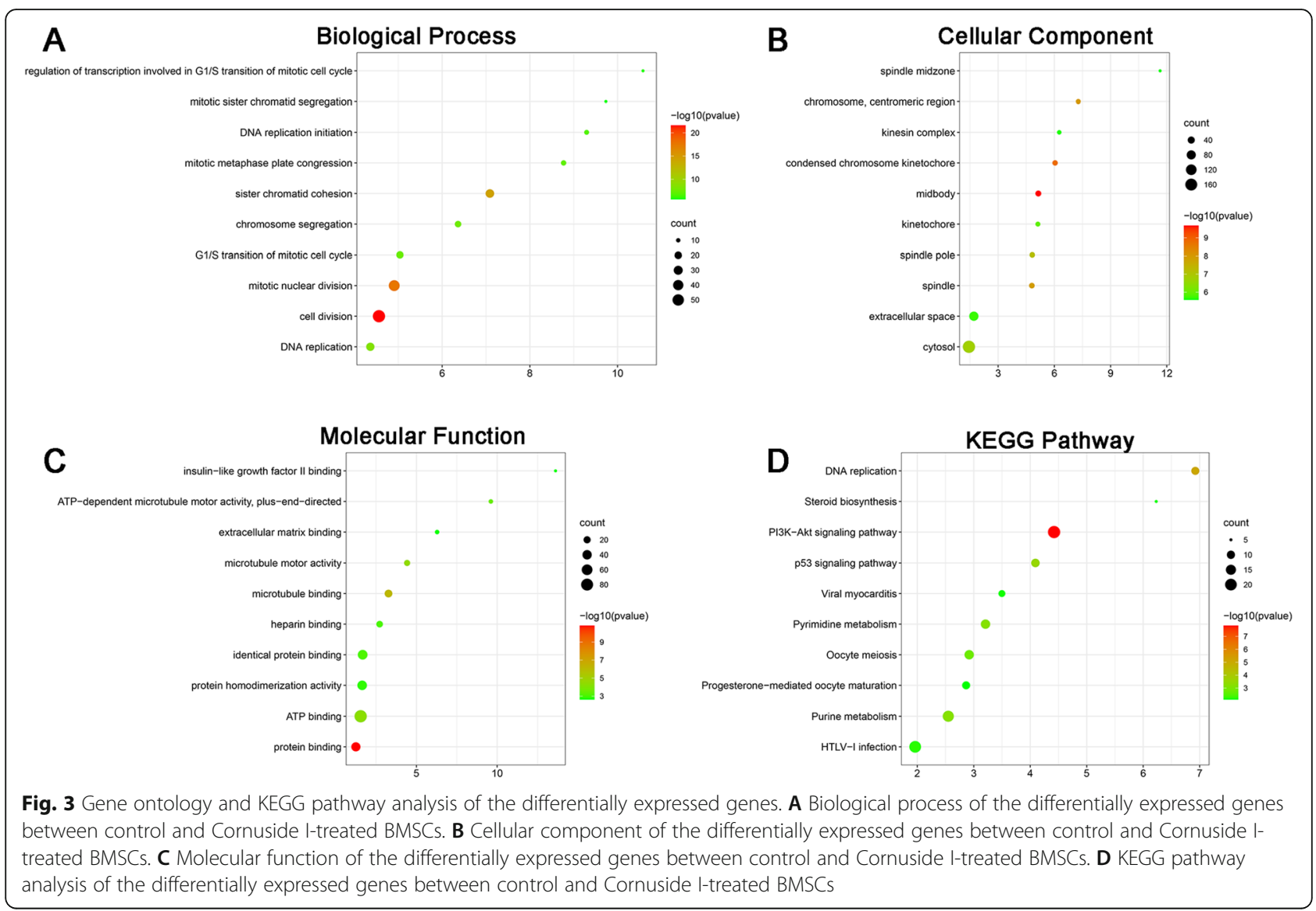

metabolism, oocyte meiosis, HTLV-I infection, viral myocarditis, steroid biosynthesis, and progesteronemediated oocyte maturation.

\section{Protein-protein interaction of the differentially expressed genes}

Figure 4 A presents the protein-protein interaction network, which included 359 nodes and 1358 edges. Further, three functional subnet modules (MCODE model 1, MCODE model 2, and MCODE model 3) were selected from the PPI network (Fig. 4B).

\section{Cornuside I promoted osteogenic differentiation of BMSCs}

To identify the role of Cornuside I in promoting osteogenic differentiation of BMSCs. To evaluate the effects of Cornuside I on the osteogenic responses of BMSCs in vitro, ALP and ARS were performed.

ALP and ARS results also showed that the Cornuside I (30 mM) group had higher ALP activity and calcium deposition than the control group and other dose of Cornuside I groups (Fig. 5A). Gene expression of osteogenic differentiation markers RUNX2, OSX, and CON was detected by qRT-PCR and western blot assays. Osteogenic differentiation markers RUNX2, OSX, and CON were significantly increased in Cornuside I (30 mM) group than other groups $(\mathrm{P}<0.05$, Fig. $5 \mathrm{~B})$. Western blot analysis was in agreement with the quantitative real-time PCR (qRT-PCR) results, showing that the protein expression of RUNX2, OSX, and CON was upregulated in the Cornuside I (30 mM) group (Fig. 5C).

\section{Cornuside I activated the PI3K/AKT signaling pathway during osteogenic differentiation of BMSCs}

To identify the mechanism of Cornuside I in promoting osteogenic differentiation of BMSCs, we firstly revealed the PI3K and Akt gene expressions in control and Cornuside I-treated BMSC groups. We found that PI3K and Akt expression were significantly upregulated in Cornuside I-treated BMSC group $(\mathrm{P}<0.05)$. Western blot analysis was in agreement with the quantitative real-time PCR (qRT-PCR) results, showing that the protein expression of $\mathrm{p}$-PI3K and p-Akt was significantly upregulated in the Cornuside I (30 mM) group (Fig. 5C).

\section{LY294002 partially blocked the promotion effects of Cornuside I on osteogenic differentiation of BMSCs}

ALP and ARS results also showed that the Cornuside I (30 mM) group had higher ALP activity and calcium deposition than the control group and other dose of 


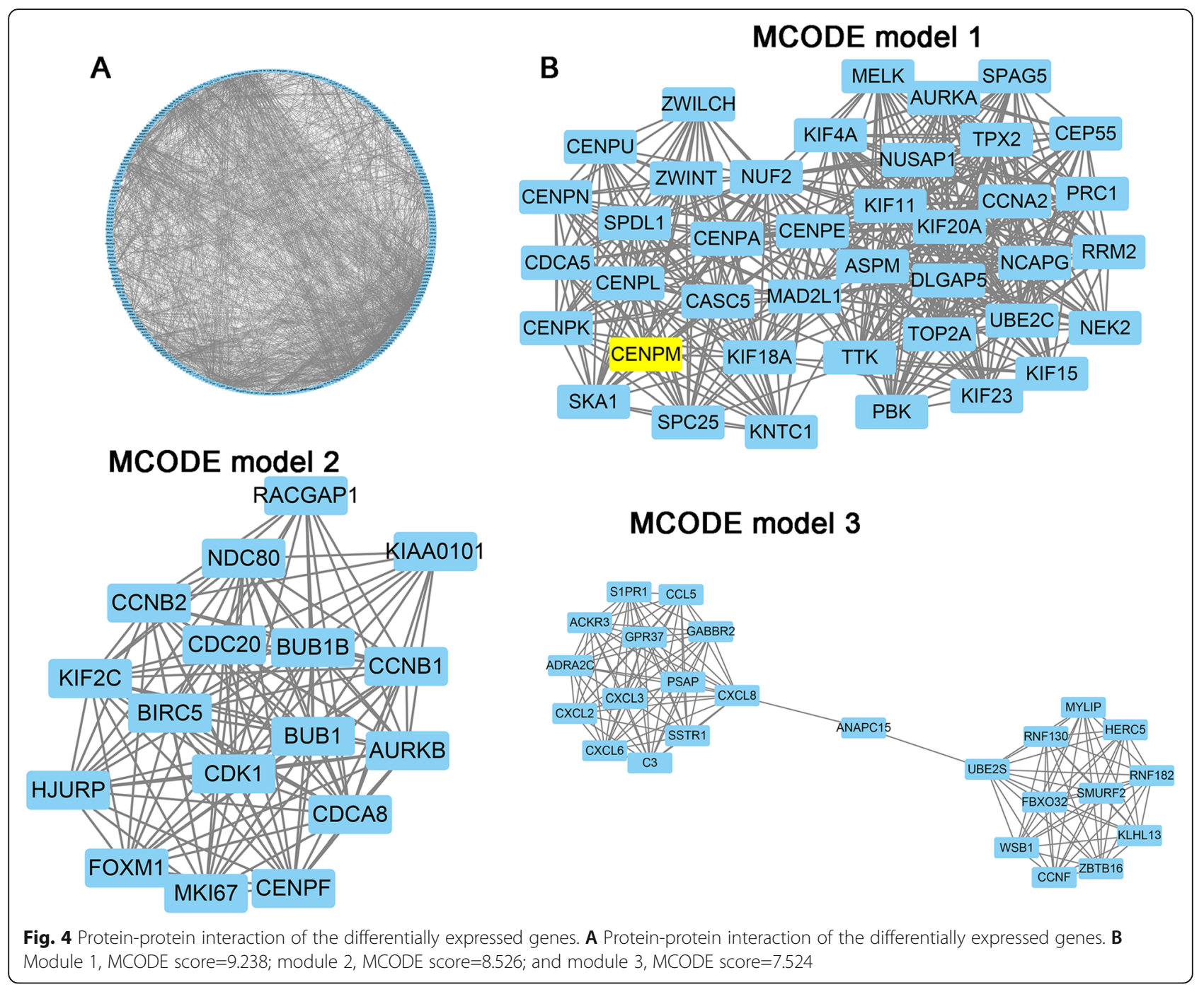

Cornuside I groups (Fig. 6A). However, the promotion effects of Cornuside I on osteogenic differentiation of BMSCs were partially blocked by LY294002 (Fig. 6A). PCR results found that Cornuside I significantly increased the PI3K and Akt expression, while LY294002 significantly downregulated the PI3K and Akt expression (Fig. 6B). Western blot analysis was in agreement with the quantitative real-time PCR (qRT-PCR) results, which suggested that LY294002 significantly downregulated the RUNX2, OSX, and CON expression (Fig. 6C).

\section{Discussion}

This study aimed to explore the role and mechanism of Cornuside I in promoting osteogenic differentiation of BMSCs. We performed RNA sequencing to compare gene expression patterns between Cornuside I and control BMSCs. Bioinformatic analysis revealed that Cornuside I mainly affects the PI3K/Akt signaling pathway. We finally summarized that Cornuside I promotes the osteogenic differentiation of BMSCs via activation of PI3K/AKT signaling pathway.

$V$. officinalis is a traditional Chinese Medicine for nourishing the liver and kidney. Previous studies have identified that $V$. officinalis could affect the function of osteoblasts and osteoclasts and finally increase the bone mineral density. Cornus officinalis possess potential antiallergic, anti-inflammatory, and antioxidant activities [20]. PI3K/AKT signaling pathway is crucial in cell proliferation, differentiation, and adaptation [21, 22]. Previous study found that PTEN/PI3K/Akt/HIF-1 $\alpha$ pathway significantly enhanced bone regeneration in critical size defects [23]. Previous study also suggest that PI3K-AKT-mTOR signal pathway is an important regulator of the osteogenic/dentinogenic differentiation of stem cells [24].

Therefore, PI3K/AKT signaling pathway is crucial for bone formation and bone regeneration. In this study, we firstly performed RNA sequencing to identify the differentially expressed genes in Cornuside I-treated BMSCs. 


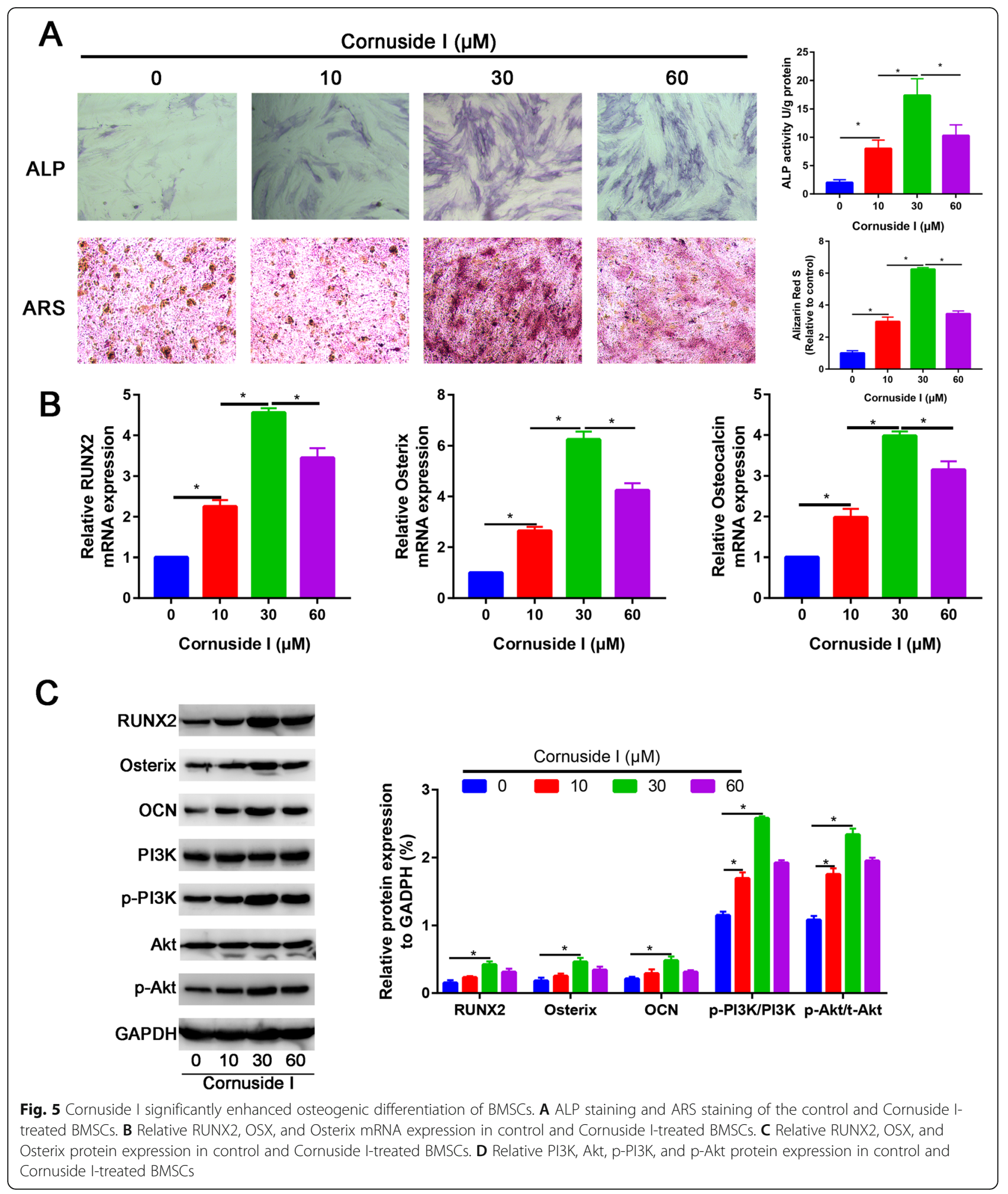

A total of 704 differentially expressed genes were identified between Cornuside I and normal BMSCs. These differentially expressed genes are mainly enriched in cell division and mainly participated into the PI3K/Akt signaling pathway. Therefore, we further performed ALP and ARS staining to identify the role of Cornuside I in promoting osteogenic differentiation of BMSCs. Many functions of the PI3K/Akt signaling pathway are mainly accomplished by p-Akt phosphorylating. We measured the $\mathrm{p}$-PI3K and $\mathrm{p}$-Akt expression in control and 


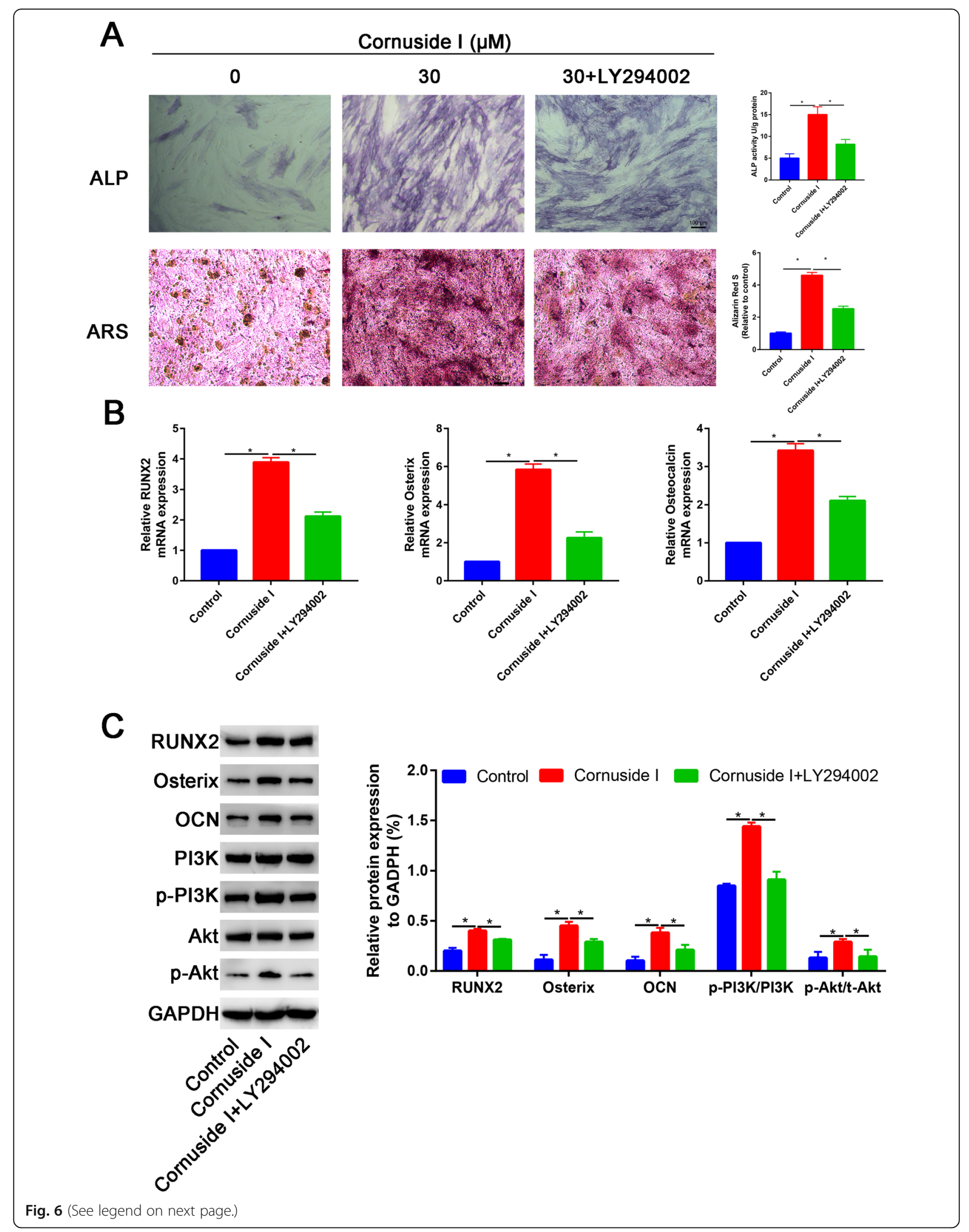


(See figure on previous page.)

Fig. 6 LY294002 partially blocked the promotion effects of Cornuside I on osteogenic differentiation of BMSCs. A ALP staining and ARS staining in control, Cornuside I, and Cornuside I + LY294002 groups. B Relative RUNX2, OSX, and Osterix mRNA expression in control, Cornuside I, and Cornuside I + LY294002 groups. C Relative RUNX2, OSX, and Osterix protein expression in control, Cornuside I, and Cornuside I + LY294002 groups. D Relative PI3K, Akt, p-PI3K, and p-Akt protein expression in control, Cornuside I, and Cornuside I + LY294002 groups

Cornuside I-treated BMSCs. Cornuside I significantly increased the p-PI3K and p-Akt expression than control group, which suggested that Cornuside I activated the PI3K/Akt signaling pathway. To further identify the mechanism of Cornuside I in promoting osteogenic differentiation of BMSCs. We administrated PI3K/Akt pathway inhibitor, LY294002 to further illustrate the Cornuside I on osteogenic differentiation of BMSCs. The promotion effects of Cornuside I could be partially blocked by LY294002. These results suggested that Cornuside I significantly increased the osteogenic differentiation of BMSCs through PI3K/Akt signaling pathway.

\section{Conclusion}

In summary, this is the first study exploring the role and mechanism of Cornuside I in promoting osteogenic differentiation of BMSCs using RNA sequencing. We finally found that Cornuside I promotes the osteogenic differentiation of BMSCs via activation of PI3K/AKT signaling pathway.

\section{Abbreviations}

BMSCs: Bone mesenchymal stem cells; CCK-8: Cell Counting Kit-8;

ALP: Alkaline phosphatase; ARS: Alizarin Red Staining; OP: Osteoporosis; MSCs: Mesenchymal stem cells; RNA-Seq: RNA sequencing; FBS: Fetal bovine serum; DEGs: Differentially expressed genes; GO: Gene ontology; KEGG: Kyoto Encyclopedia of Genes and Genomes; BP: Biological process; MF: Molecular function; CC: Cellular component; MCODE: Molecular Complex Detection; PBS: Phosphate-buffered saline; RT-PCR: Real-time polymerase chain reaction

\section{Acknowledgements}

Not applicable.

\section{Authors' contributions}

FG, SLX, and XHW performed RNA sequencing. XXZ and JW performed the cell isolation. FG and SLX wrote the primary manuscript. XXZ and JW edited the final manuscript. The authors read and approved the final manuscript.

\section{Funding}

This work was funded by Top-100 Talent Cultivation Plan of Shanghai University of Medicine and Health Science (ZPBRK-18-07), the construction of key discipline group of Sanitary System of Shanghai Pudong New District (PWZxq2017-12), and the Featured Clinical Discipline Project of Shanghai Pudong New District (PWYts2018-02).

\section{Availability of data and materials}

All the data pertaining to the present study will be willingly shared upon reasonable request.

\section{Declarations}

Ethics approval and consent to participate Not applicable.

\section{Consent for publication}

Not applicable.

\section{Competing interests}

The authors declare that they have no competing interests.

\section{Author details}

'Shanghai University of Medicine \& Health Sciences Affiliated Zhoupu Hospital, Shanghai Pudong New District Zhoupu Hospital, Shanghai 201318, China. ${ }^{2}$ Department of Orthopedics, Shanghai Fifth People's Hospital Affiliated to Fudan University, No. 801, Heqing Road, Minhang District, Shanghai 200240, China.

Received: 7 May 2021 Accepted: 23 May 2021

Published online: 21 June 2021

\section{References}

1. Wang Y, Tao Y, Hyman ME, Li J, Chen Y. Osteoporosis in China. Osteoporos Int. 2009;20(10):1651-62. https://doi.org/10.1007/s00198-009-0925-y.

2. Lamichhane AP. Osteoporosis-an update. JNMA J Nepal Med Assoc. 2005;44:60-6.

3. Coughlan T, Dockery F. Osteoporosis and fracture risk in older people. Clin Med (Lond). 2014;14(2):187-91. https://doi.org/10.7861/ clinmedicine.14-2-187.

4. Liu GF, Wang ZQ, Liu L, Zhang BT, Miao YY, Yu SN. A network meta-analysis on the short-term efficacy and adverse events of different anti-osteoporosis drugs for the treatment of postmenopausal osteoporosis. J Cell Biochem. 2018;119(6):4469-81. https://doi.org/10.1002/jcb.26550.

5. Kanis JA. Assessment of fracture risk and its application to screening for postmenopausal osteoporosis: synopsis of a WHO report. WHO Study Group. Osteoporos Int. 1994;4(6):368-81. https://doi.org/10.1007/bf01622200.

6. Zhao Z, Ma X, Ma J, Sun X, Li F, Lv J. Naringin enhances endothelial progenitor cell (EPC) proliferation and tube formation capacity through the CXCL12/CXCR4/PI3K/Akt signaling pathway. Chem Biol Interact. 2018;286: 45-51. https://doi.org/10.1016/j.cbi.2018.03.002.

7. Song $N$, Zhao Z, Ma X, Sun X, Ma J, Li F, et al. Naringin promotes fracture healing through stimulation of angiogenesis by regulating the VEGFNEGFR2 signaling pathway in osteoporotic rats. Chem Biol Interact. 2017;261:11-7. https://doi.org/10.1016/j.cbi.2016.10.020.

8. Sanders S, Geraci SA. Osteoporosis in postmenopausal women: considerations in prevention and treatment: (women's health series). South Med J. 2013;106(12):698-706. https://doi.org/10.1097/SMJ.0b013 e3182a0df8b.

9. Li Y, Jin D, Xie W, Wen L, Chen W, Xu J, et al. Mesenchymal stem cellsderived exosomes: a possible therapeutic strategy for osteoporosis. Curr Stem Cell Res Ther. 2018;13(5):362-8. https://doi.org/10.2174/1574888×13 666180403163456.

10. Macías I, Alcorta-Sevillano N, Rodríguez Cl. Osteoporosis and the potential of cell-based therapeutic strategies. Int J Mol Sci. 2020;21(5):1653. https:// doi.org/10.3390/ijms21051653.

11. Jiang $Y$, Zhang $P$, Zhang $X$, Lv L, Zhou $Y$. Advances in mesenchymal stem cell transplantation for the treatment of osteoporosis. Cell Prolif. 2021;54(1): e12956. https://doi.org/10.1111/cpr.12956.

12. Yuan F, Peng W, Yang C, Zheng J. Teriparatide versus bisphosphonates for treatment of postmenopausal osteoporosis: a meta-analysis. Int J Surg. 2019; 66:1-11. https://doi.org/10.1016/j.jisu.2019.03.004.

13. Black DM, Rosen CJ. Clinical Practice. Postmenopausal osteoporosis. N Engl J Med. 2016;374(3):254-62. https://doi.org/10.1056/NEJMcp1513724.

14. Tella SH, Gallagher JC. Prevention and treatment of postmenopausal osteoporosis. J Steroid Biochem Mol Biol. 2014;142:155-70. https://doi.org/1 0.1016/j.jsbmb.2013.09.008

15. Dong Y, Feng ZL, Chen HB, Wang FS, Lu JH. Corni Fructus: a review of chemical constituents and pharmacological activities. Chin Med. 2018;13(1): 34. https://doi.org/10.1186/s13020-018-0191-z. 
16. Niu D, An S, Chen X, Bi H, Zhang Q, Wang T, et al. Corni Fructus as a natural resource can treat type 2 diabetes by regulating gut microbiota. Am J Chin Med. 2020;48(06):1385-407. https://doi.org/10.1142/s0192415×20500688.

17. Wang $L$, Chen $H$, Jiang $Y$, Liu Z, Wang $Q$, Zheng $X$. Simultaneous determination of 11 high-polarity components from fructus corni: a quantitative LC-MS/MS method for improved quality control. J Chromatogr Sci. 2018;56(1):56-64. https://doi.org/10.1093/chromsci/bmx083.

18. Wang Y, Wu JZ, Li Y. Polysaccharides of fructus corni improve ovarian function in mice with aging-associated perimenopause symptoms. Evid Based Complement Alternat Med. 2019;2019:2089586-8. https://doi.org/1 $0.1155 / 2019 / 2089586$

19. Park E, Lim E, Yeo S, Yong Y, Yang J, Jeong SY. Anti-menopausal effects of Cornus officinalis and Ribes fasciculatum extract in vitro and in vivo. Nutrients. 2020;12(2). https://doi.org/10.3390/nu12020369.

20. Quah Y, Lee SJ, Lee EB. Cornus officinalis ethanolic extract with potential anti-allergic, anti-inflammatory, and antioxidant activities. Nutrients. 2020; 12(11):3317. https://doi.org/10.3390/nu12113317.

21. Zhang W, Bai X, Zhao B, Li Y, Zhang Y, Li Z, et al. Cell-free therapy based on adipose tissue stem cell-derived exosomes promotes wound healing via the PI3K/Akt signaling pathway. Exp Cell Res. 2018;370(2):333-42. https://doi. org/10.1016/j.yexcr.2018.06.035

22. Wu R, Ruan J, Sun Y, Liu M, Sha Z, Fan C, et al. Long non-coding RNA HIF1A-AS2 facilitates adipose-derived stem cells (ASCs) osteogenic differentiation through miR-665/L6 axis via PI3K/Akt signaling pathway. Stem Cell Res Ther. 2018;9(1):348. https://doi.org/10.1186/s13287-018-1082-z.

23. Yang C, Liu X, Zhao K, Zhu Y, Hu B, Zhou Y, et al. miRNA-21 promotes osteogenesis via the PTEN/PI3K/Akt/HIF-1a pathway and enhances bone regeneration in critical size defects. Stem Cell Res Ther. 2019;10(1):65. https://doi.org/10.1186/s13287-019-1168-2.

24. Zheng H, Tian Y, Gao Q, Yu Y, Xia X, Feng Z, et al. Hierarchical micro-nano topography promotes cell adhesion and osteogenic differentiation via integrin a2-PI3K-AKT signaling axis. Front Bioeng Biotechnol. 2020;8:463. https://doi.org/10.3389/fbioe.2020.00463.

\section{Publisher's Note}

Springer Nature remains neutral with regard to jurisdictional claims in published maps and institutional affiliations.

Ready to submit your research? Choose BMC and benefit from:

- fast, convenient online submission

- thorough peer review by experienced researchers in your field

- rapid publication on acceptance

- support for research data, including large and complex data types

- gold Open Access which fosters wider collaboration and increased citations

- maximum visibility for your research: over $100 \mathrm{M}$ website views per year

At $\mathrm{BMC}$, research is always in progress.

Learn more biomedcentral.com/submissions 